Supporting Information

\title{
Assembly of Disordered Cocontinuous Morphologies by Multiblock Copolymers with Random Block Sequence and Length Dispersity
}

Di Zeng, Rohit Gupta, E. Bryan Coughlin, Ryan C. Hayward*

Department of Polymer Science and Engineering, University of Massachusetts Amherst

120 Governors Drive, Amherst, MA 01003-9263, United States

*email: hayward@umass.edu

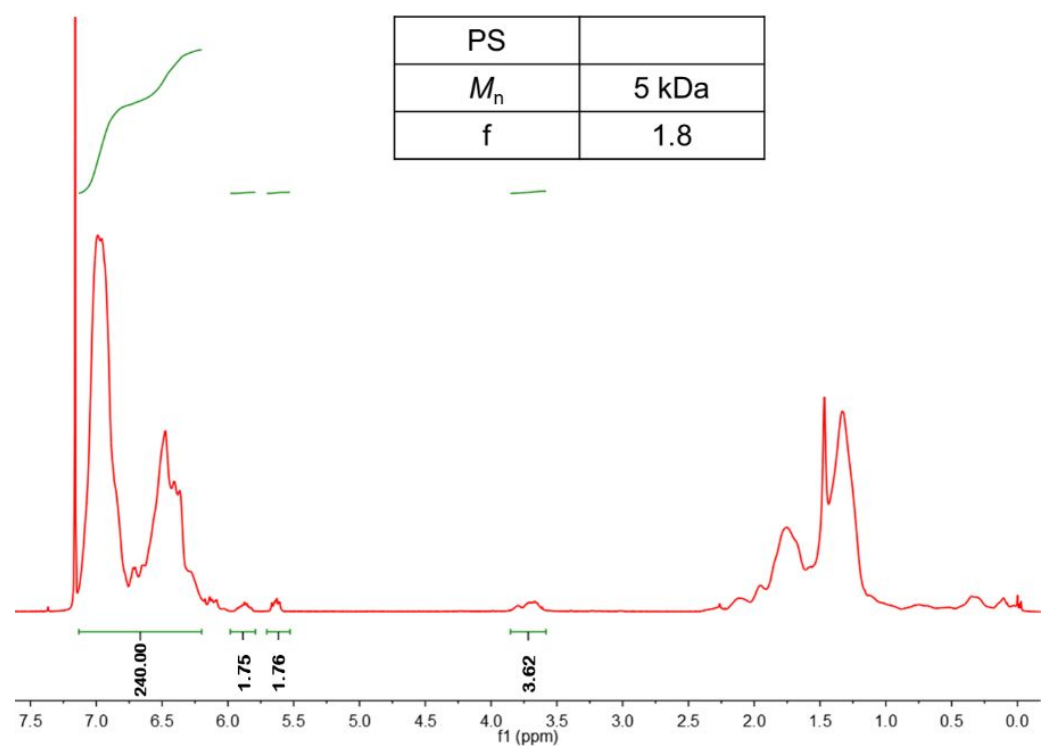

Figure S1. ${ }^{1} \mathrm{H} \mathrm{NMR}$ in $\mathrm{CDCl}_{3}$ of $\mathrm{PS}(5.0 \mathrm{~kg} / \mathrm{mol})$ functionalized with acrylate end groups.

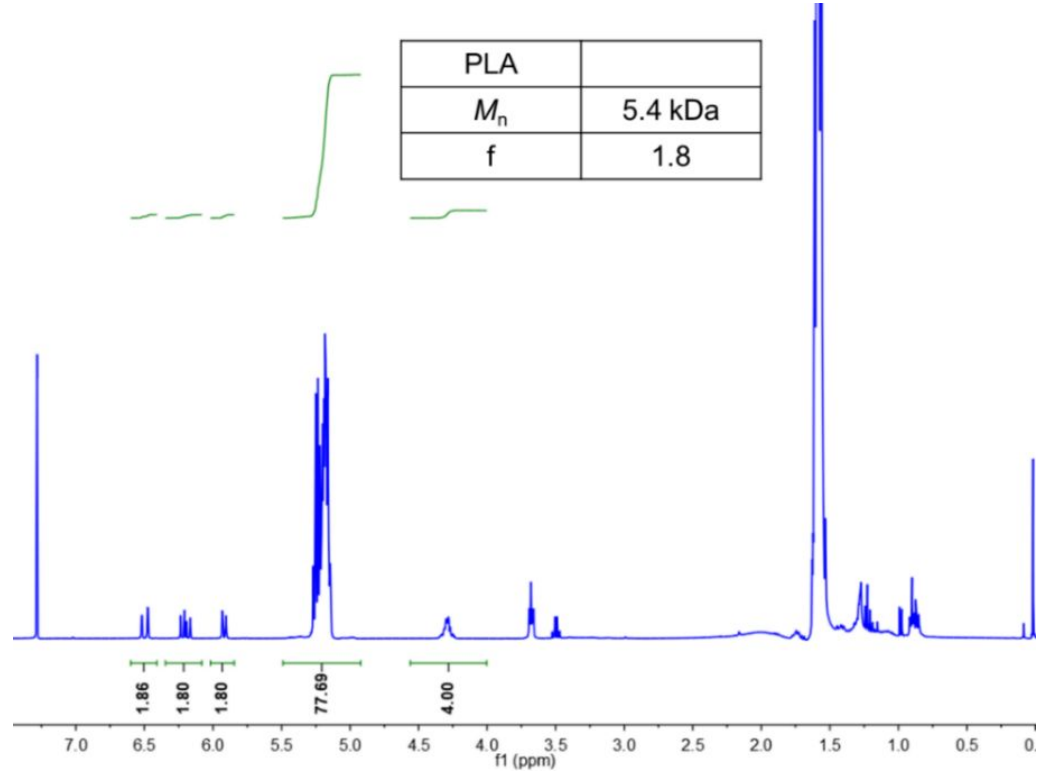

Figure S2. ${ }^{1} \mathrm{H}$ NMR in $\mathrm{CDCl}_{3}$ of PLA ( $\left.5 \mathrm{~kg} / \mathrm{mol}\right)$ functionalized with acrylate end groups. The molecular weight estimated from NMR by comparing the initiator peak at $4.3 \mathrm{ppm}$ to the backbone methine proton peak at $5.3 \mathrm{ppm}$ is $5.7 \mathrm{~kg} / \mathrm{mol}$, close to the PS-equivalent GPC molecular weight of $5.4 \mathrm{~kg} / \mathrm{mol}$. 


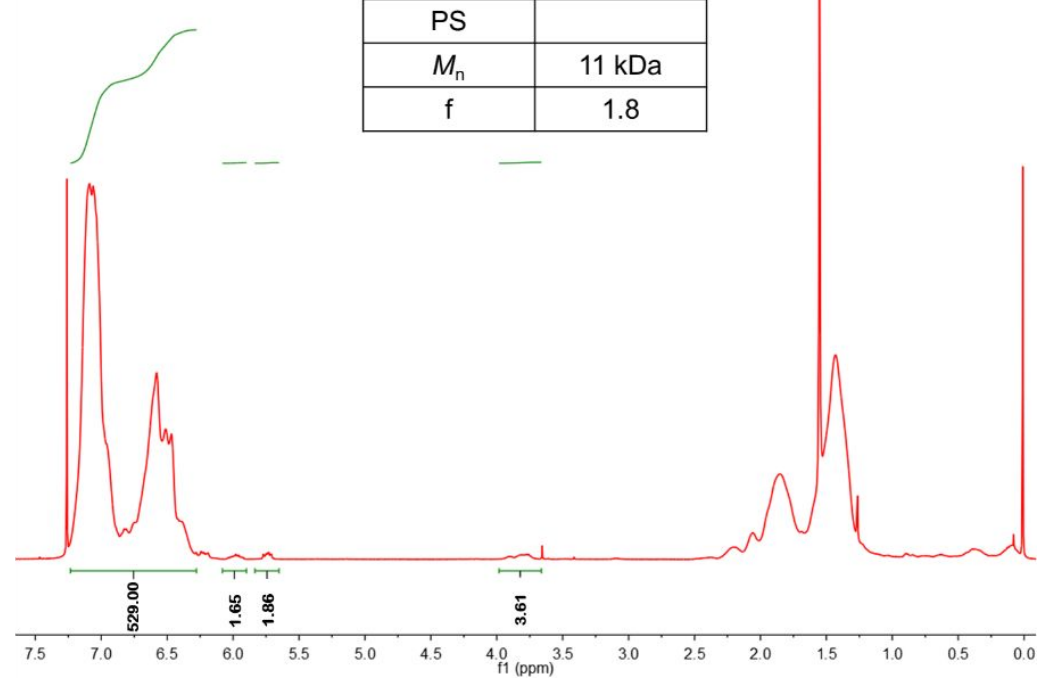

Figure S3. ${ }^{1} \mathrm{H}$ NMR in $\mathrm{CDCl}_{3}$ of PS $(11 \mathrm{~kg} / \mathrm{mol})$ functionalized with acrylate end groups.

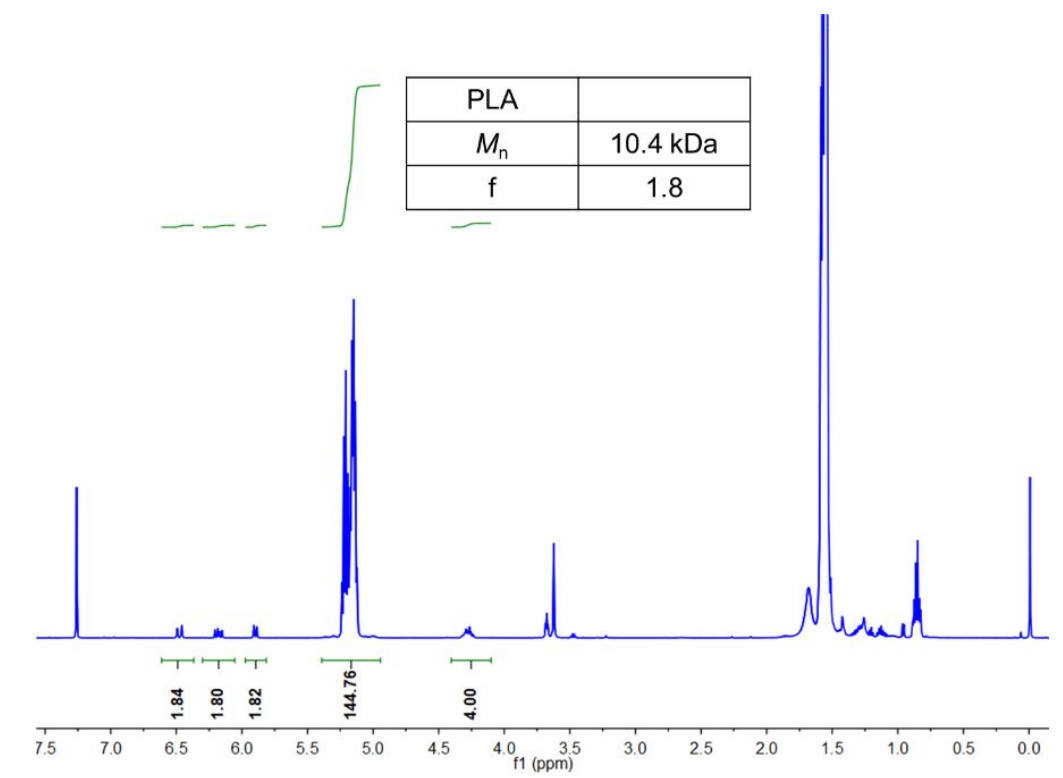

Figure S4. ${ }^{1} \mathrm{H}$ NMR in $\mathrm{CDCl}_{3}$ of PLA $(10 \mathrm{~kg} / \mathrm{mol})$ functionalized with acrylate end groups. The molecular weight estimated from NMR is $10.6 \mathrm{~kg} / \mathrm{mol}$, while the PS-equivalent GPC molecular weight is $10.4 \mathrm{~kg} / \mathrm{mol}$. 

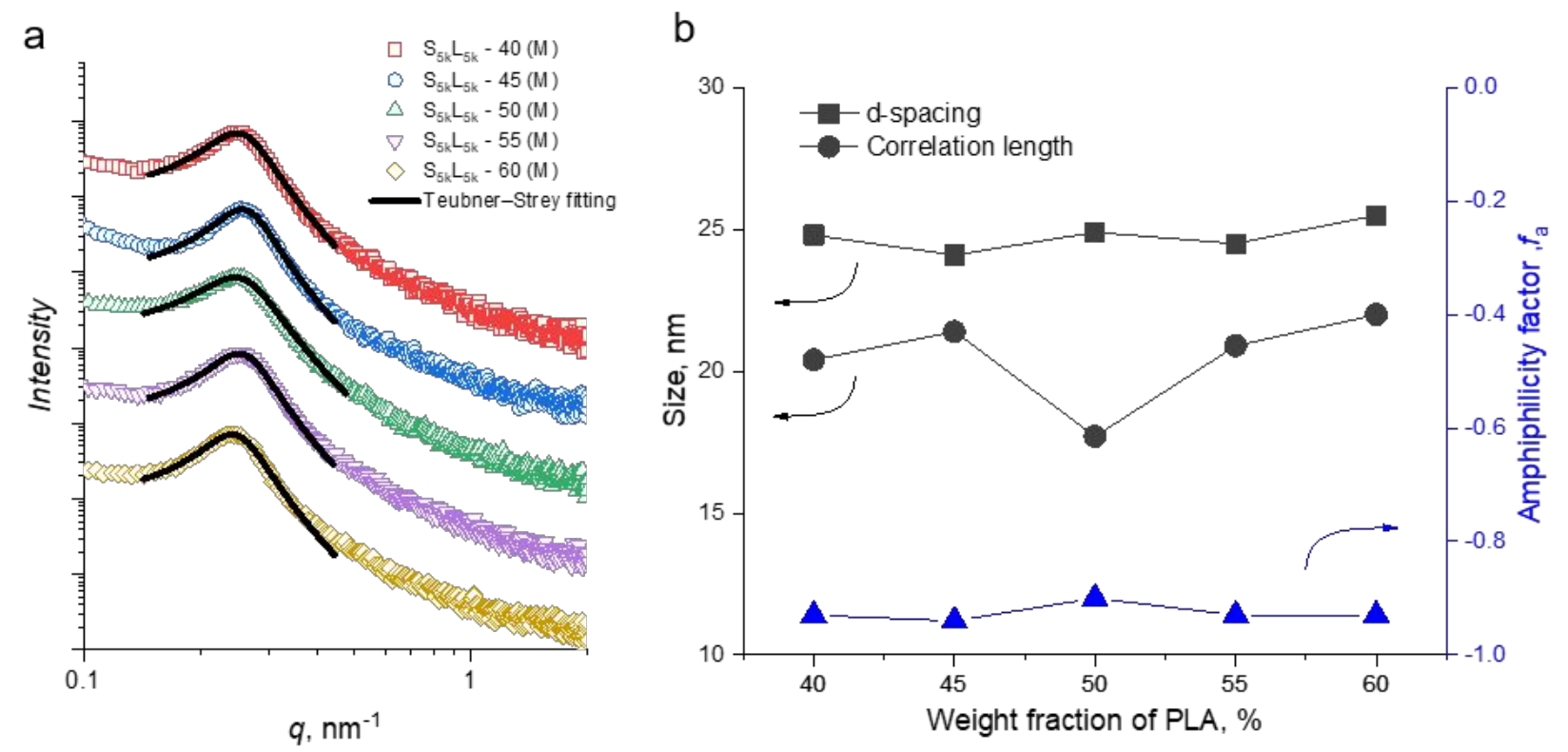

Figure S5. (a) SAXS data (offset vertically for visibilty) for $S_{5 k} L_{5 k}(M)$ samples in the cocontinuous region, with fits to the 3-parameter Teubner-Strey model (solid curves). (b) Plots of the fit parameters as a function of PLA weight fraction.

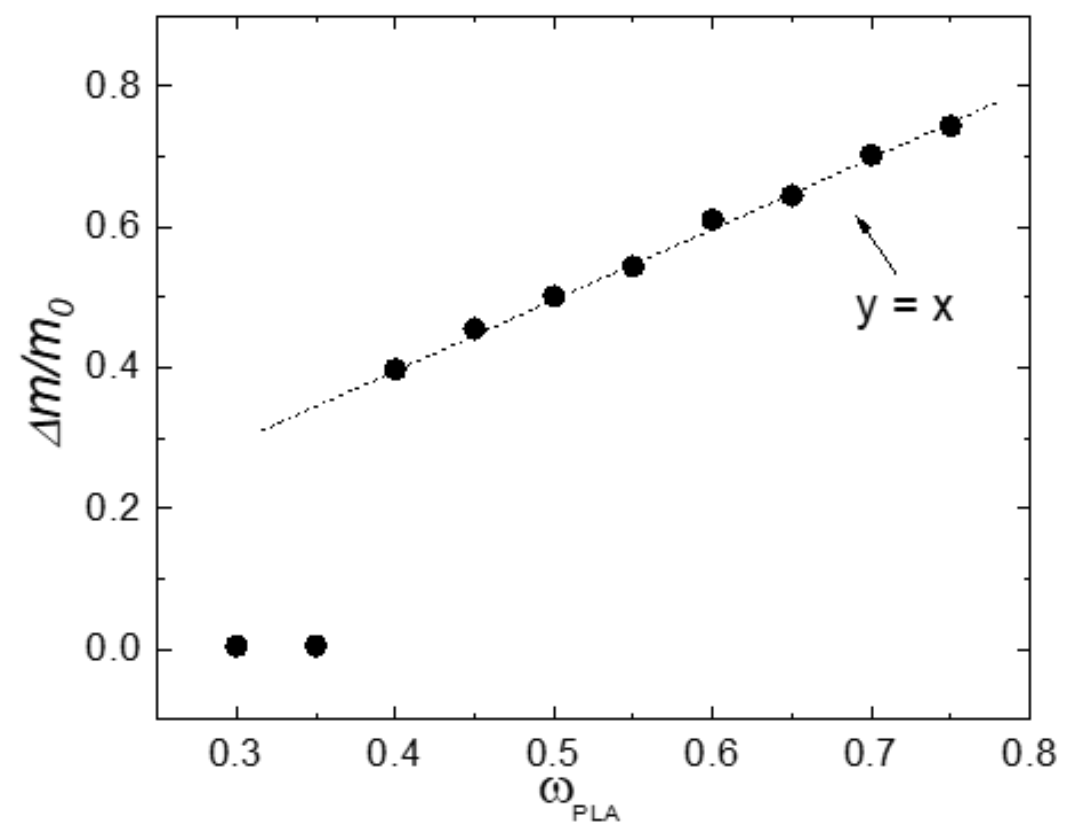

Figure S6. Mass loss $\Delta m$ normalized by initial mass $m_{0}$ after etching of $\mathrm{S}_{5 \mathrm{k}} \mathrm{L}_{5 \mathrm{k}}(\mathrm{M})$ samples in basic solution. The dotted line $y=x$ corresponds to quantitative removal of the PLA fraction. 


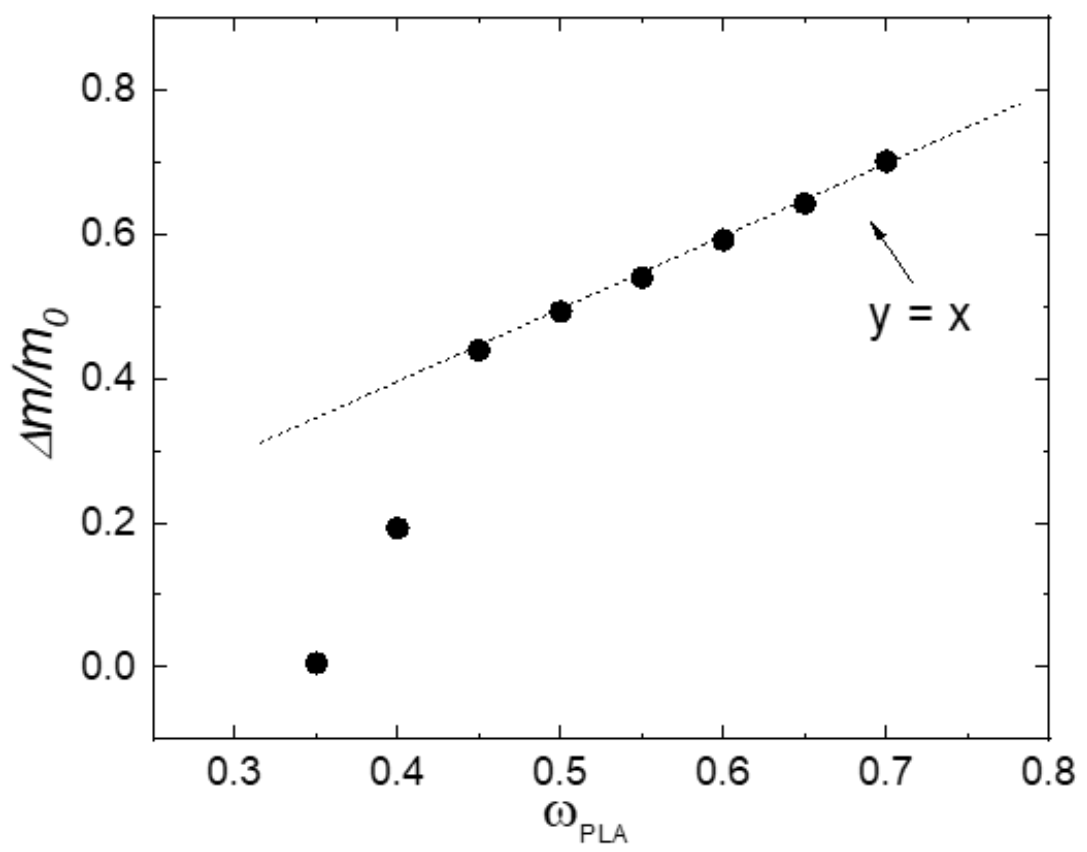

Figure S7. Normalized mass loss after etching of $\mathrm{S}_{11 \mathrm{k}} \mathrm{L}_{10 \mathrm{k}}(\mathrm{M})$ samples.

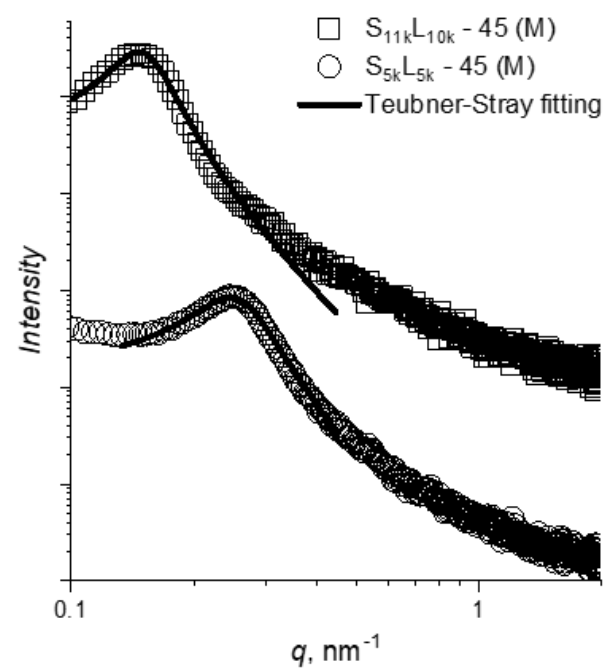

\begin{tabular}{|l|l|l|l|}
\hline & $\begin{array}{l}\text { d-spacing, } \\
\mathrm{nm}\end{array}$ & $\begin{array}{l}\text { Correlation } \\
\text { length, } \zeta, \\
\mathrm{nm}\end{array}$ & $\begin{array}{l}\text { amphiphilicity } \\
\text { factor, } f_{\mathrm{a}}\end{array}$ \\
\hline $\mathrm{S}_{5_{\mathrm{k}}} \mathrm{L}_{\mathrm{F}_{\mathrm{k}}}-45(\mathrm{M})$ & 24.1 & 21.4 & -0.94 \\
\hline $\mathrm{S}_{11 \mathrm{k}} \mathrm{L}_{10 \mathrm{k}}-45(\mathrm{M})$ & 42.1 & 37.1 & -0.93 \\
\hline
\end{tabular}

Figure S8. SAXS data (offset vertically for visibility) for $S_{5 k} L_{5 k}(M)-45$ and $S_{11 k} L_{10 k}(M)-45$ samples, with fits to the Teubner-Strey model (solid curves). 


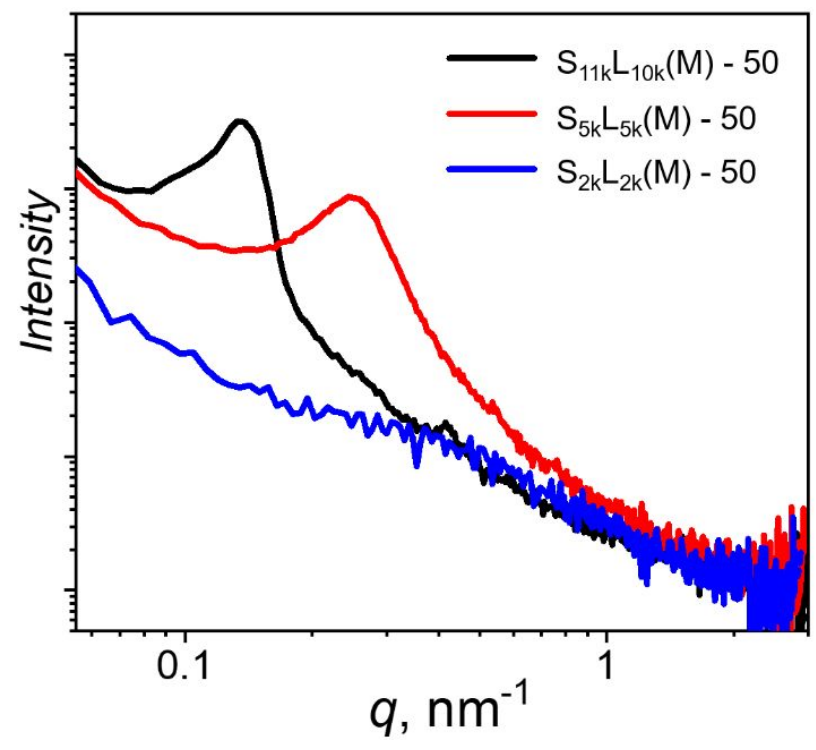

Figure S9. SAXS data for PS/PLA MBCs $\left(\omega_{\mathrm{PLA}}=0.5\right)$ with different strand lengths $M$, representing different segregation strengths of $\chi\left(N_{\mathrm{PS}}+N_{\mathrm{PLA}}\right)=6,15$, and 30 . 